\title{
Production and Optimization of Mevastatin using Penicillium citrinum NCIM 768
}

\author{
Narayanan Mahesh ${ }^{1 *}$, Srinivasan Balakumar ${ }^{1}$, P. Indumathi' ${ }^{1}$ Arunadevi Ayyadurai ${ }^{1}$ and Rangarajan Vivek ${ }^{2}$
}

${ }^{1}$ Department of Chemistry and Biosciences, Srinivasa Ramanujan Centre, Sastra University, Kumbakonam -612001, India ${ }^{2}$ Department of Biotechnology, Indian Institute of Technology, Kharagpur-721 302, India

\begin{abstract}
A modified solid-state fermentation was used to produce mevastatin by Penicillium citrinum NCIM 768 recycling wheat bran as carrier. The following optimum conditions of physiochemical parameters of temperature $27^{\circ} \mathrm{C}, \mathrm{pH} 4$ with a relative humidity of $60 \%$ and at an inoculum volume of $2.5 \mathrm{ml}$, resulted in mevastatin yield of $68.7 \mathrm{mg} \mathrm{L}^{-1}$ in fermentation broth. Among various nitrogen and carbon sources, addition of sodium nitrate and glucose improved mevastatin production.
\end{abstract}

Keywords: Mevastatin; Anticholesterol; Penicillium citrinum; Solid fermentation; Secondary metabolite

\section{Introduction}

Mevastatin, also known as compactin or ML-236B, is a member of the class of statins belonging to the polypeptide groups and it is a hypocholesterimic agent has been an attractive molecule over the last few decades, for its anticholesterol activity [1]. It is soluble in ethanol and dimethyl sulfoxide. Mevastatin was highly effective in lowering the total and low-density lipoprotein (LDL) cholesterol in both experimental animals and patients with primary hypercholesterolemia [2].

The hypocholesterolemic effect of statins lies in the reduction of the very low-density lipoproteins [VLDL] and LDL involved in the translocation of cholesterol [3], and in the increased level of highdensity lipoproteins [HDL] [4], with a subsequent reduction of the LDL to HDL-cholesterol ratio, which is the best predictor of atherogenic risk [5].

Mevastatin, a secondary metabolite and its derivative is a potent competitive inhibitor of 3-hydroxyl-3-methylglutaryl coenzyme A [HMG-COA] reductase [6], which is a regulatory enzyme for cholesterol biosynthesis. This is a rate-limiting enzyme in cholesterol synthesis in humans and act as a useful drug against atherosclerosis. Pravastatin can also be obtained by the biotransformation of mevastatin by Streptomyces carbophilus [7].

Mevastatin has been produced in submerged fungal fermentation of glucose medium using Penicillium citrinum, NCIM 768 in the recent years, there has been increasing interest in the use of solid-state fermentation $[\mathrm{SSF}]$. In the current study, we used wheat bran as a carrier in solid state fermentation for the production of mevastatin [8].

\section{Materials and Methods}

\section{Procurement of microorganism}

Penicillium citrinum NCIM 768 was procured from NCL, Pune, India. The culture was maintained in Potato Dextrose Agar (PDA) slants.

\section{Inoculum preparation}

The water soluble extract of soybean meal (40g soybean was kept in $1000 \mathrm{ml}$ of distilled water at $4^{\circ} \mathrm{C}$ under stirring conditions for 6 days) was prepared. $\mathrm{pH}$ of the medium was adjusted to 6.3 and sterilized in the autoclave at $121^{\circ} \mathrm{C}$ for 20 minutes at 15 Psi. After sterilization the medium was inoculated with spore suspension at $1 \% \mathrm{v} / \mathrm{v}$ and incubated at $28^{\circ} \mathrm{C}, 220 \mathrm{rpm}$ in an orbital shaker for $26 \mathrm{~h}$.

\section{Solid state fermentation (SSF)}

Solid state growth experiments were conducted in $250 \mathrm{ml}$ Erlenmeyer flasks containing $10 \mathrm{~g}$ of wheat bran moistened with 1:1 mineral salt solution $\left[\mathrm{g} \mathrm{L}^{-1} ; \mathrm{K}_{2} \mathrm{HPO}_{4} ; \mathrm{NaCl} ; \mathrm{MgSO}_{4} .7 \mathrm{H}_{2} \mathrm{O} ; \mathrm{FeSO}_{4}\right]$ [9], Flasks were sterilized by autoclaving for $15 \mathrm{~min}$ at $121^{\circ} \mathrm{C}$. After sterilization, the flasks were cooled and inoculated with $5 \mathrm{ml}$ spore suspension $\left(10^{7}-10^{8}\right.$ Spores $\left.\mathrm{mL}^{-1}\right)$ and incubated at $37^{\circ} \mathrm{C}$ for $144 \mathrm{hrs}$ $[10,11]$, Samples were taken for analysis of mevastatin production for every $24 \mathrm{~h}$. All the experiments were carried out in triplicates and the results were expressed in mean with standard deviations.

\section{Optimization of $\mathrm{pH}$, temperature and inoculum volume}

Optimization of various process parameters were carried out to enhance production of mevastatin under solid state growth conditions. The growth studies were carried out considering different parameters such as temperature, $\mathrm{pH}$ of the medium and the volume of inoculum. Experiments were performed using wheat bran as a substrate with different $\mathrm{pH}$ ranges from $2-6$ and it was kept at $60 \%$ relative humidity [9], Likewise the solid substrate was kept at different temperature ranged from $27^{\circ} \mathrm{C}, 37^{\circ} \mathrm{C}, 45^{\circ} \mathrm{C}, 50^{\circ} \mathrm{C}$ and $60^{\circ} \mathrm{C}$. Fermentation was carried out with different inoculum from 1.5 to $3.5 \mathrm{ml}$ to get optimum inoculum volume for maximum production of mevastatin.

\section{Supplementation with different carbon and nitrogen sources}

Different carbon sources such as glucose, fructose, sucrose, maltose

*Corresponding author: Narayanan Mahesh, Department of Chemistry and Biosciences, Srinivasa Ramanujan Centre, Sastra University, Kumbakonam 612001 India, Tel: 91-4352426823; Fax: 91-4352402460; E-mail: magi.mbbt@gmail.com

Received November 23, 2011; Accepted January 17, 2012; Published January 23, 2012

Citation: Mahesh N, Balakumar S, Indumathi P, Ayyadurai A, Vivek R (2012) Production and Optimization of Mevastatin using Penicillium citrinum NCIM 768 . J Microbial Biochem Technol 4: 001-004. doi:10.4172/1948-5948.1000063

Copyright: @ 2012 Mahesh N, et al. This is an open-access article distributed under the terms of the Creative Commons Attribution License, which permits unrestricted use, distribution, and reproduction in any medium, provided the original author and source are credited 
and starch and nitrogen sources such as urea, peptone, yeast extract, sodium nitrate and ammonium sulphate on mevastatin production were also studied. These sources were supplemented with wheat bran concentration of $1 \%(\mathrm{w} / \mathrm{w})$ on dry basis, to see their effects on mevastatin production. The final moisture content $60 \%$ was maintained throughout the study.

\section{Loss of organic matter}

Material was dried before and after fermentation up to constant weight. Loss of Organic Matter (LOM) was calculated as the weight difference and expressed as a percentage of the initial dry weight of the samples.

\section{$\mathrm{LOM}=\left(\mathrm{W}_{\mathrm{i}}-\mathrm{W}_{\mathrm{f}} / \mathrm{W}_{\mathrm{i}}\right) \mathrm{X} 100 \%$}

Where $W_{i}$ is the initial dry weight of solid material before fermentation and $\mathrm{W}_{\mathrm{f}}$ is the final dry weight of solid material after fermentation.

It was assumed that the loss of organic matter is due to $\mathrm{CO}_{2}$ formation by fungal metabolic activities during the course of fermentation. Since there is no direct method for biomass estimation in SSF, LOM was used to express biomass and metabolic activity in an indirect way.

\section{Estimation of mevastatin}

At the end of fermentation, the biomass was treated with $50 \mathrm{ml}$ of distilled water and agitated thoroughly on orbital shaker for 30 minutes. The whole contents were filtered through whattman No.1 filter paper and absorbance was read to quantify the mevastatin based on the standard chart plotted using standard sigma grade mevastatin $(\lambda \max =238 \mathrm{~nm})$ using UV spectrophotometer [12].

\section{Results and Discussion}

A detailed study was carried out for mevastatin production by Penicillium citrinum NCIM 768 in solid state fermentation using wheat bran as a substrate. Solid substrate other than wheat bran causes agglomeration, which in turn affects mixing, results in the heat accumulation, improper heat transfer and causes reduction in the mevastatin production [13], Since, low cost solid substrates are used solid-state fermentation has been preferred over submerged fermentation. And different combinations of solid substrates were studied to determine if these could be used to formulate a commercially attractive substrate. Only the wheat bran - barley combination has served reasonably well for the mevastatin production.

\section{Selection of the carrier}

Wheat bran and Barley were used as carriers for the production of mevastatin by solid state fermentation. Among them, wheat bran enhanced the maximum yield of mevastatin production and it was found to be $68.7 \mathrm{mg} \mathrm{L}^{-1}$ at $60 \%$ humidity \& $27^{\circ} \mathrm{C}$ temperature for 6 days of fermentation. The Loss of Organic Matter with $60 \%$ moisture was obtained as $30.29 \%$. A Loss of Organic matte above $30 \%$ indicates that the fungal growth has almost ceased. This in turn would terminate the synthesis of mevastatin.

The selection of suitable moisture content has been considered as one of the important parameters in the optimization of solid state fermentation. Moisture content has been reported to influence the physical properties of the substrates. High moisture content in the substrate would reduce the porosity of the bed, resulting in poor oxygen transfer into the compact bed. On the other hand, low moisture content is also detrimental, as they convert the vegetative cells into spores; thereby both the biomass and product yields are affected.

\section{Effect of temperature on mevastatin production}

The solid-state fermentation process at $60 \%$ of relative humidity was carried out at different temperature of incubation to get optimal temperature for maximum production of mevastatin viz $27^{\circ} \mathrm{C}, 37^{\circ} \mathrm{C}$,

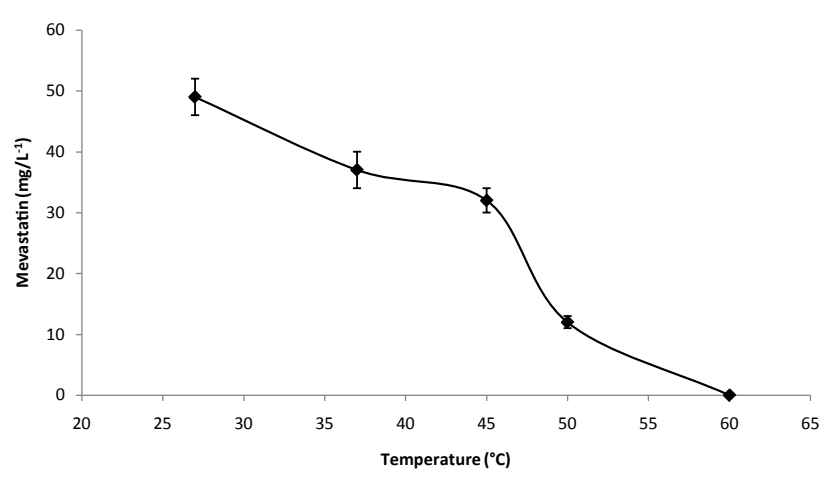

Figure 1: Effect of Temperature on Mevastatin Production.

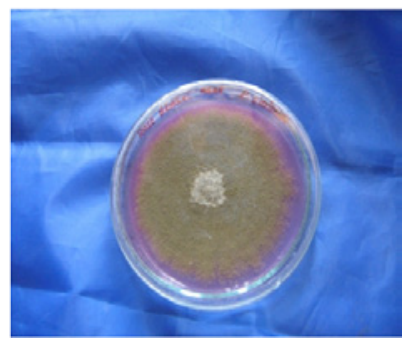

Plate 1: Aerial view of Pencillium citrinum.

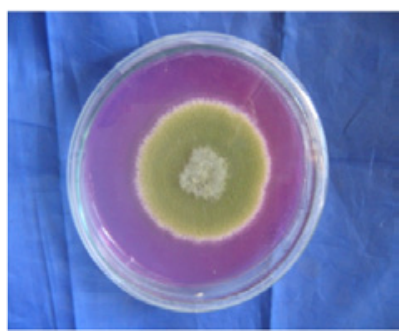

Plate 2: Initial growth of Pencillium citrinum in Rose Bengal agar.

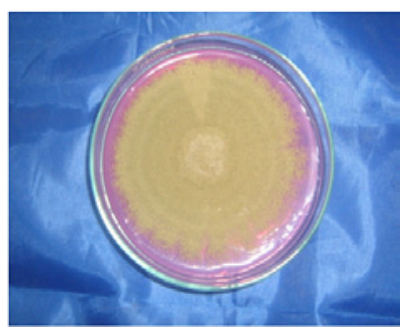

Plate 3: Back view of Pencillium citrinum. 
$45^{\circ} \mathrm{C}, 50^{\circ} \mathrm{C} \& 60^{\circ} \mathrm{C}$ with wheat bran. It was found that $27^{\circ} \mathrm{C}$ as the optimum temperature yielding mevastatin of $49.6 \mathrm{mg} \mathrm{L}^{-1}$ after 6 days of fermentation (Figure 1). Plates $[1,2,4,10,13]$, show the culture of Penicillium citrinum growth on agar plates (Plates 1 to 3 ), its microscopic view (Plate 4) and growth in solid state medium (Plate 5).

\section{Effect of $\mathrm{pH}$ on the production medium}

By maintaining other conditions at optimum level (i.e., temperature of incubation at $27^{\circ} \mathrm{C}$, relative humidity at $60 \%$ ), maximum mevastatin

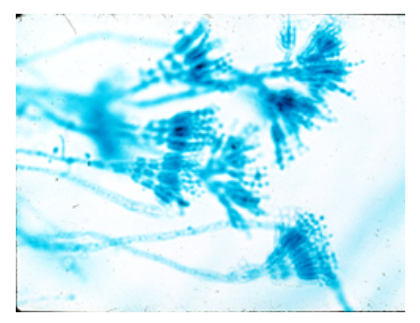

Plate 4: Microscopic view of Pencillium citrinum.

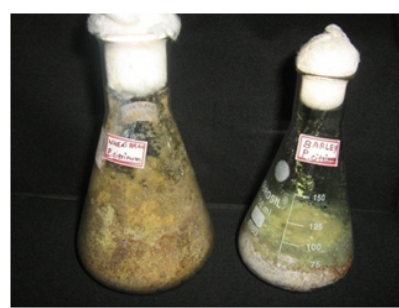

Plate 5: Mevastatin Production in flasks

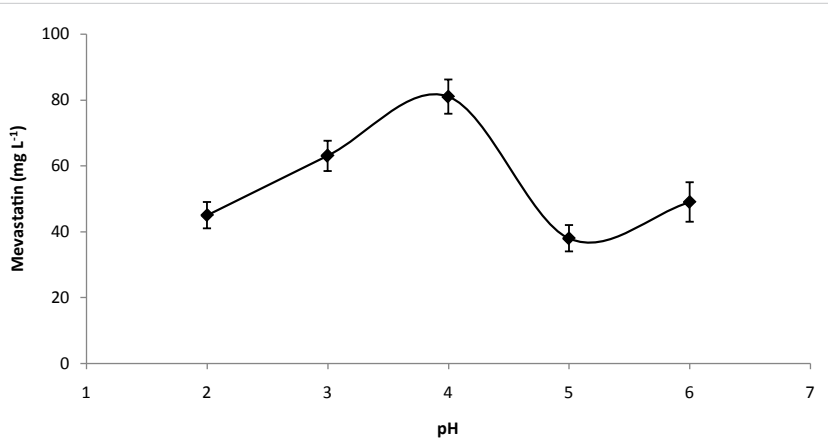

Figure 2: Effect of $\mathrm{pH}$ on Mevastatin Production.

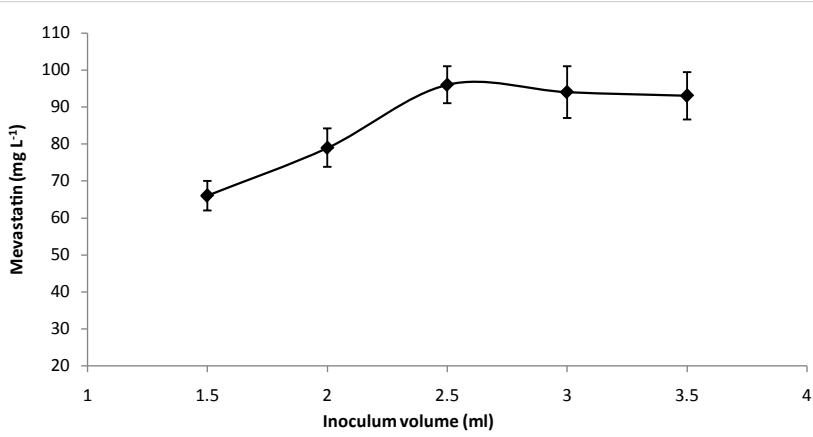

Figure 3: Effect of Inoculum volume on Mevastatin Production.

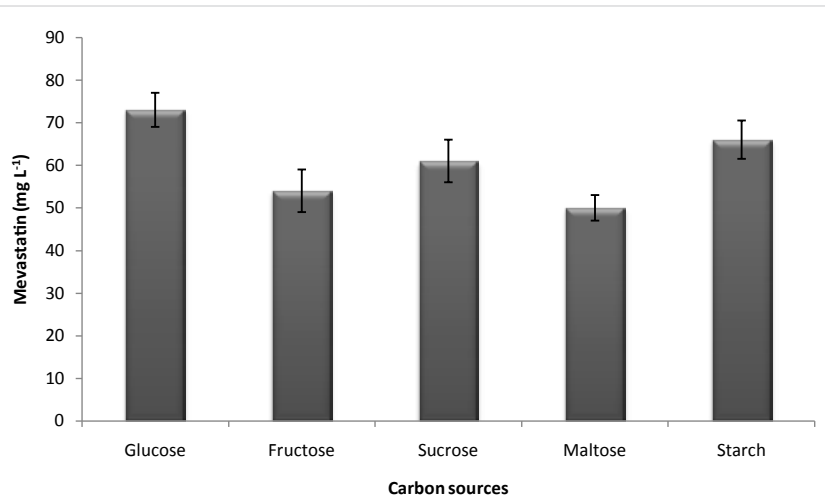

Figure 4: Effect of Carbon source on Mevastatin Production

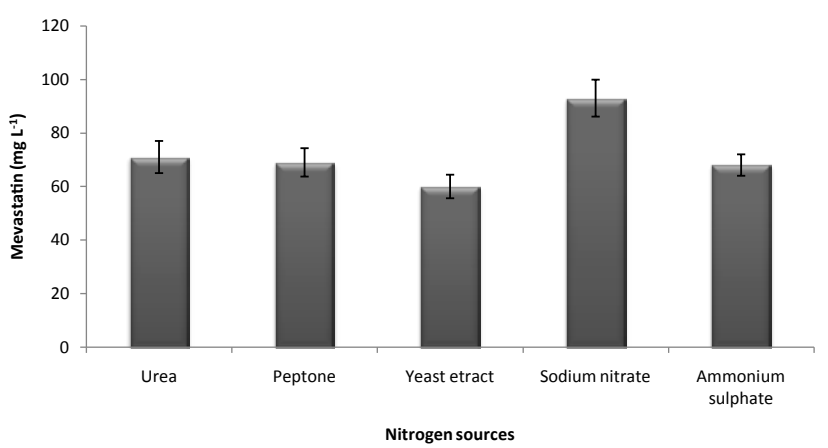

Figure 5: Effect of Nitrogen source on Mevastatin Production.

production of $81.7 \mathrm{mg} \mathrm{L}^{-1}$ was obtained at initial $\mathrm{pH}$ of 4 (Figure 2).

\section{Effect of seed volume (Inoculum Volume)}

Fermentation was carried out with different inoculum from 1.5 to $3.5 \mathrm{ml}$ to get optimum inoculum volume for maximum production of mevastatin with wheat bran, temperature at $27^{\circ} \mathrm{C}$ and at relative humidity of $60 \%$. It was found that at inoculum volume of $2.5 \mathrm{ml}$ produced mevastatin of $96.3 \mathrm{mg} \mathrm{L}^{-1}$ after 6 days of incubation (Figure $3)$.

The higher production of mevastatin is obtained at inoculum volume of $2.5 \mathrm{ml}$. It was observed that the increase in the mevastatin production was attributed by the drop in biomass growth. Acidic environment at $\mathrm{pH} 4$ with $60 \%$ moisture favored the transfer of metal ions and other vital nutrients into fungal cells required for metabolic reactions of the organisms resulting in better product formation. Mevastatin production was optimum at $144 \mathrm{~h}$ of incubation at $27^{\circ} \mathrm{C}$ and it found to be $68.7 \mathrm{mg} \mathrm{L}^{-1}$.It was also observed that there was no further increase in the mevastatin production after $144 \mathrm{~h}$ of incubation. This observation prompted us to fix $144 \mathrm{~h}$ as the optimal incubation time for the harvest of the product from the solid substrate.

\section{Effect of carbon source}

Fermentation was carried out with different carbon sources (1\%) such as glucose, fructose, sucrose, maltose and starch to get the maximum production of mevastatin with wheat bran, while keeping other conditions at optimum level. It was found that among the carbon source, glucose enhanced the yield of mevastatin production as 73.1 $\mathrm{mg} \mathrm{L}^{-1}$ (Figure 4). 


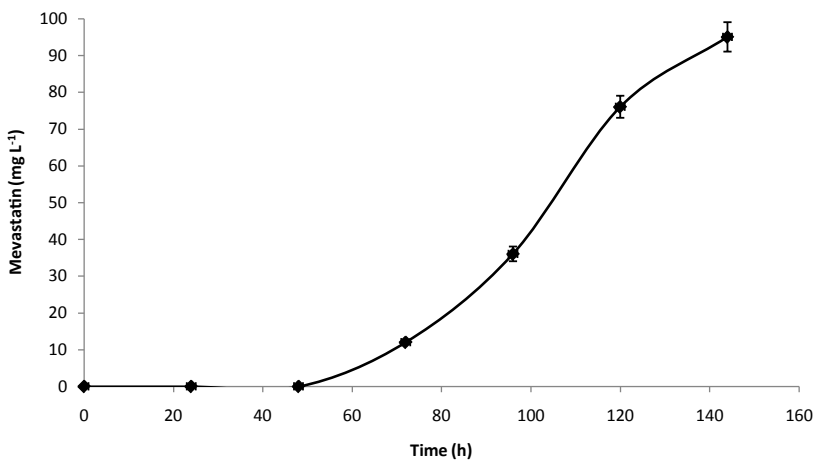

Figure 6: Time course of mevastatin production at optimal conditions.

\section{Effect of nitrogen source}

Fermentation was carried out with different nitrogen sources (1\%) such as urea, peptone, yeast extract, sodium nitrate and ammonium sulphate to get the maximum production of mevastatin with wheat bran, while keeping other conditions at optimum level. It was found that the nitrogen source, sodium nitrate an inorganic source enhanced the high yield of mevastatin production as $93.6 \mathrm{mg} \mathrm{L}^{-1}$ (Figure 5).

Finally experiments carried out at the optimal conditions obtained, resulted in the mevastatin production of $95 \mathrm{mg} \mathrm{L}^{-1}$. (Figure 6) shows the time course of mevastatin production at the optimal conditions of physicochemical parameters. It can be observed from the graph that the mevastatin production started after $4^{\text {th }}$ day, indicating the onset of the stationary phase, which in turn favored the mevastatin production.

In the present research, addition of different nitrogen additives to wheat bran resulted in better yield. Among them, sodium nitrate enhanced mevastatin production. Likewise, addition of different carbon additives to wheat bran resulted in better yield. Among them, addition of glucose exhibited better mevastatin production [14]. The prediction of loss of organic matter with sufficient moisture is due to $\mathrm{CO}_{2}$ formation by fungal metabolic activities during the course of fermentation.

When these results are compared with the literature [13], some variations were observed due to the change in the environmental condition and various levels of physical parameters.

\section{References}

1. Chakravarti R, Sahai V (2004) Compactin-a review. Appl Microbiol Biotechnol 64: 618-624.

2. Barrios-Gonzalez J, Miranda RU (2010) Biotechnological production and applications of statins. Appl Microbiol Biotechnol 85: 869-883.

3. Quesney-Huneeus V, Wiley MH, Siperstein MD (1979) Essential role for mevalonate synthesis in DNA replication. Proc Natl Acad Sci USA 76: 50565060.

4. Alberts AW, Chen J, Kuron G, Hunt V, Huff J, et al. (2000) Mevinolin: a highly potent competitive inhibitor of hydroxylmethyl glutaryl-CoA reductase and a cholesterol lowering agent. Journal of Proc Natl Acad Sci USA 77: 3957-3961.

5. Manzoni M, Rollini M (2002) Biosynthesis and biotechnological production of statins by filamentous fungi and application of these cholesterol-lowering drugs. Appl Microbiol and Biotechnol 58: 555-564.

6. Tobert JA (1987) New developments in lipid-lowering therapy: the role of inhibitors of hydroxymethylglutaryl-coenzyme A reductase. Circulation 76: $534-$ 538 .
7. Singh RP, Kumar R, Kapur N (2003) Molecular regulation of cholesterol biosynthesis: implications in carcinogenesis. J Environ Pathol Toxicol Oncol 22: 75-92.

8. Chakravarti R, Sahai V ( 2002) Optimization of compactin production in chemically defined medium by penicillium citrinum using statistical method. Process Biochem 38: 481-486.

9. Shaligram NS, Singh SK, Singhal RS, Pandey A, Szakacs G (2009) Compactin Production studies using penicillium brevicompactum under Solid-State Fermentation Conditions. Appl Biochem biotechnol 159: 505-520.

10. Chakravarti R, Sahai V (2000) A Chemically-defined medium for production of compactin by penicillium citrinum. Biotechnol Lett 24: 527-530.

11. Suryanarayan S (2003) Current industrial practice in solid-state fermentations for secondary metabolite production: the Biocon India experience. Biochem Eng J 13: 189-195

12. Shiao MS, Don HS (1987) Biosynthesis of mevinolin a hypocholesterolemic fungal metabolite in Aspergillus terrus. Proc Natl Sci Conc Repub China B 11 223-231.

13. Ahamad MZ, Panda BP, Javed S, Ali M (2006) Production of mevastatin by solid-state fermentation using wheat bran as substrate. Res J Microbiol 1: 443447.

14. Seenivasan A, Subhagar S, Aravindan R, Viruthagiri T (2008) Microbial production and biomedical applications of lovastatin. Indian J Pharm 70: 701 709

15. Endo A, Monacolin K (1979) A new hypocholesterolemic agent produced by Monascus species. J Antibiot 32: 852-854.

16. Yang $Y$, Zhang L, Zou RX (2009) Study on the crystallization process of mevastatin by FBRM. Chinese Journal of Antibiot 34: 471-474. 